\title{
0 cuidado domiciliar com a água de consumo humano e suas implicações na saúde: percepções de moradores em Vitória (ES)
}

\author{
Home care with water for human consumption and its implications in health: \\ perceptions of residents in Vitória (ES), Brazil
}

\begin{abstract}
Sara Ramos da Silva
Engenheira Civil. Mestre em Engenharia Ambiental pela Universidade Federal do Espírito Santo (UFES). Doutora em Saneamento, Meio Ambiente e Recursos Hídricos pela Universidade Federal de Minas Gerais (UFMG). Professora da Coordenadoria de Saneamento Ambiental do Instituto Federal do Espírito Santo (Ifes)
\end{abstract}

\section{Léo Heller}

Engenheiro Civil. Doutor em Epidemiologia pela UFMG. Pós-Doutorado em Políticas Públicas pela Universidade de Oxford. Professor-associado do Departamento de Engenharia Sanitária e Ambiental da UFMG

\section{Jorge de Campos Valadares}

Psicólogo. Engenheiro Civil. Mestre em Urbanismo pela Universidade de Paris I (Pantheon-Sorbonne). Doutor em Saúde Pública pela Fundação Oswaldo Cruz (Fiocruz). Pesquisador titular da Fiocruz. Professor do Departamento de Saneamento e Saúde Ambiental da Escola Nacional de Saúde Pública (ENSP)

\section{Sandy Cairncross}

Engenheiro de Saúde Pública. Doutor em Mecânica dos Solos pela Universidade de Cambridge. Professor do Departamento de Doenças Infecciosas e Tropicais da Escola Londrina de Higiene e Medicina Tropical da Universidade de Londres (LSHTM)

\section{Resumo}

Hábitos domiciliares incorretos no manejo da água de consumo humano podem afetar a saúde de seus usuários. Entrevistas realizadas com quatro grupos de dez moradores no município de Vitória (ES) alertam para esse risco. Para a análise dos depoimentos, foi aplicada metodologia qualitativa, empregando-se a estratégia do Discurso do Sujeito Coletivo. Os discursos apontam para a falta de conhecimento dos usuários acerca da manutenção correta do reservatório e filtro domiciliares de água, para a desconfiança da qualidade da água recebida do sistema público e a falta de um canal de comunicação efetivo entre a população, o serviço de saneamento e as instituições de saúde pública locais. A pesquisa mostra a necessidade de se reverem as formas de comunicação com a população atualmente adotadas por essas instituições.

Palavras-chave: água para consumo humano; cuidados domiciliares; discurso do sujeito coletivo; equipamentos domiciliares; riscos à saúde.

\begin{abstract}
Wrong domiciliary habits with regard to the management of water consumption may affect the health of its users. Interviews conducted with four groups of ten residents in Vitória (ES), Brazil, point out the risk. For the analysis of testimonials, the qualitative methodology was applied, as employing the strategy of Collective Subject Discourse. The discourses showed the lack of knowledge of the users about the proper maintenance of the reservoir and filter household water, the mistrust on the quality of water received from the public system and the lack of an effective communication channel between the population, the water supply services and the local institutions of public health. This research shows the need to review the types of information provided to the population currently adopted by these institutions.
\end{abstract}

Keywords: water for human consumption; home care; collective subject discourse; household equipments; risk to health. 


\section{Introdução}

A garantia da qualidade da água para consumo humano no Brasil está estabelecida pela Portaria n. 518 (BRASIL, 2004). Essa Portaria ressalta as responsabilidades, por parte de quem produz a água, a quem cabe o exercício de controle de qualidade da água, das autoridades sanitárias, a quem cabe a missão de vigilância da qualidade da água, como também dos órgãos de controle ambiental, no que se refere ao monitoramento e ao controle das águas dos mananciais de acordo com seu uso como fonte de abastecimento destinada ao consumo humano. A ampla difusão e a implementação dessa Portaria no País constituem importante instrumento para o efetivo exercício da vigilância e do controle da qualidade da água para consumo humano, com vistas a garantir a prevenção de doenças e a promoção da saúde da população.

O direito do cidadão de receber as informações sobre a qualidade da água que consome é estabelecido pelo Decreto n. 5.440 (BRASIL, 2005), que define como devem ser esses procedimentos de informação à população, tanto pelos responsáveis pelos serviços de abastecimento de água como pelas autoridades responsáveis pela vigilância da qualidade da água. A partir da promulgação desse Decreto, foi legalmente garantido à população o direito de receber, nas contas mensais de água, as seguintes informações: locais, formas de acesso e contatos por meio dos quais as informações ficam disponíveis e orientações sobre os cuidados necessários em situações de risco à saúde. Quanto aos deveres da população em relação à água de consumo humano, vale lembrar que a Portaria n. 518 (BRASIL, 2004) estabelece procedimentos que buscam garantir a qualidade da água até a entrada no domicílio. O usuário tem, portanto, um papel importante na garantia da continuidade dessa qualidade no interior do domicílio. Deve-se dar especial atenção às tubulações, reservatórios e equipamentos de tratamento de água, bem como às práticas de higiene domiciliares.

A Associação Brasileira de Normas Técnicas (ABNT) orienta sobre o projeto, construção e manutenção dos reservatórios domiciliares de água (ABNT, 1998). Esses cuidados visam à não-transmissão de cor, odor, toxidade e à não-proliferação de micro-organismos na água. A literatura registra vários estudos que mostram o risco que a população está exposta devido à presença do reservatório domiciliar de água e falta dos cuidados necessários. Mostram que o problema é encontrado dentro das residências, pois a água coletada dentro dos reservatórios domiciliares muitas vezes não se encontra em conformidade com os padrões de potabilidade (AMARAL et al., 2003; CAMILOTTI; GONÇALVES, 2003; ROCHA et al., 2006; SÁ et al., 2005; SANTOS; COHEN; CYNAMON, 2005).

Em associação às diversas situações em que o usuário pode estar sujeito à água com qualidade imprópria, como anomalias nas estações de tratamento, contaminação da água tratada em reservatórios e rede de distribuição, ou até catástrofes, há de se ressaltar a cultura de não-confiança da população na água do sistema público, o que tem levado à utilização de filtros domésticos para tratamento da água, fontes alternativas ou consumo de água envasada.

Os filtros domésticos são usados com a intenção de melhorar a qualidade da água, porém, para ter eficácia, é imprescindível tomar certos cuidados (GUSMÃO; ARAGÃO; MAGALHÃES, 2003). Por outro lado, a inexistência de normas ou regulamentações, o grande número de tipos e a ausência ou variedades de informações dificultam a realização desses cuidados pelos consumidores. Constantemente solicitado para analisar os filtros domésticos, o Instituto Nacional de Metrologia, Normalização e Qualidade Industrial realiza suas pesquisas com base na verificação das informações na rotulagem indicada pela indústria.

A percepção pública sobre a qualidade da água para consumo humano, proveniente de sistema de abastecimento, é tema de várias pesquisas em diversas partes do mundo (GALLUP ORGANIZATION'S, 2003; JONES et al., 2005; LEVALLOIS; GRONDIN; GINGRAS, 1999; MCGUIRE, 1995; MELAKU; ISMAIL, 2002; PIRIOU et al., 2004; STRANG, 2004).

Na cidade de Vitória (ES), apesar de a maior parte da população do município ser atendida pelo serviço público de abastecimento de água, o risco de transmissão de doenças pela água ao qual a população está exposta tem sido destaque em um dos principais jornais locais (POSSEBOM, 2004; TESSAROLO, 1999; VENTURIM, 2002). Essa cidade possui uma população censitária (2002) de 282.606 habitantes e área de 93,38 km². Integra, juntamente com os municípios de Serra, Cariacica, Viana, Vila Velha, Fundão e Guarapari, a região metropolitana da grande Vitória. Dos domicílios no município, 99,50\% têm acesso à rede geral de abastecimento de água, $89,80 \%$ estão ligados à rede geral de esgotos ou de drenagem pluvial e 99,60\% são atendidos pelo serviço de coleta de resíduos sólidos da Prefeitura Municipal (PREFEITURA MUNICIPAL DE VITÓRIA, 2009). Os serviços de abastecimento de água e de coleta e tratamento de esgotos são prestados pela Companhia Espírito Santense de Saneamento (Cesan).

A partir da data prevista pela legislação, a Cesan tem informado, nas contas de água, sobre a qualidade da água recebida pela população do sistema público de abastecimento. Os procedimentos do usuário para o não-desperdício de água são veiculados em meios de comunicação, como televisão, rádio e internet. A Secretaria de Estado da Saúde tem produzido e distribuído material informativo, como cartazes e folders, que trata da importância do consumo de água com qualidade.

Assim, esta pesquisa buscou investigar os cuidados domiciliares com a água de consumo humano e suas implicações na saúde, por meio do conhecimento de aspectos pessoais do sujeito - atitudes, comportamentos e percepções -, em Vitória (ES). Foram investigados conteúdos e modalidades de apreensão da realidade que abarcassem aspectos subjetivos individuais em relação ao tema estudado 
encontrados no cotidiano, hábitos e modos de vida. O objeto de investigação está inserido no campo de interfaces entre diferentes áreas mediante uma investigação com abordagem qualitativa.

\section{Material e métodos}

\section{Delineamento metodológico e amostra}

A pesquisa foi aprovada no Comitê de Ética em Pesquisa da Universidade Federal de Minas Gerais (UFMG) (SILVA, 2007). Para o seu desenvolvimento, foi aplicado método qualitativo, empregando-se a estratégia do Discurso do Sujeito Coletivo (DSC), segundo metodologia proposta por Lefèvre e Lefèvre (2003). O método do DSC busca preservar a discursividade do sujeito pesquisado em todas as etapas da pesquisa, desde a elaboração do roteiro de perguntas, passando pela coleta, processamento e tabulação dos dados até a apresentação dos resultados. É uma forma destinada a permitir à coletividade falar diretamente sobre o tema a ser estudado. É um discurso-síntese redigido na primeira pessoa do singular e composto por expressões-chave (ECH) que têm a mesma ideia central (IC) ou ancoragem (A). Para a elaboração dos DSC, partiu-se dos discursos em estado bruto, ou seja, como apresentado nas entrevistas gravadas, sendo submetidos a um trabalho analítico inicial de decomposição, que consistiu em utilizar as figuras metodológicas (ECH, IC e A) presentes em cada um dos discursos individuais e em todos eles reunidos, e que terminou de uma forma sintética, buscando-se a reconstituição discursiva da representação social.

Para a escolha das áreas estudadas na cidade de Vitória, extraíram-se informações da pesquisa desenvolvida por Queiroz (2006). Os critérios que sustentaram essa escolha foram: existência na área de Unidade de Saúde que desenvolvesse o Programa de Monitorização das Doenças Diarreicas Agudas; maiores incidências de diarreia; localização de pontos de amostragem do Controle de Qualidade da Água e da Vigilância da Qualidade da Água que apresentassem resultados com maior proporção de violação nos parâmetros de coliformes totais, coliformes termotolerantes e cloro residual; médio e baixo nível socioeconômico. Após avaliação desses critérios, concluiu-se pela escolha das seguintes áreas: área de favela urbanizada com sistema de abastecimento de água - Mangue Seco (MSe); área de favela não-urbanizada com sistema de abastecimento de água - Santa Teresa (ST); área cuja base econômica predominante é a pesca - Ilha das Caieiras (ICa); área com médio nível socioeconômico - Jardim Camburi (JC).

A escolha dos sujeitos para participarem da pesquisa ocorreu de forma intencional, com o apoio de agentes comunitárias de saúde do Programa de Saúde da Família (PSF) em ST e ICa e de líderes comunitárias em MSe e JC. Essa escolha pautou-se pela observação dos itens: conhecimento do indivíduo sobre o bairro e seus moradores; localização da residência, procurando-se adequada distribuição espacial nas áreas de estudo; disposição do morador a participar. Procurou-se estabelecer uma amostra exemplar. Foram visitadas 48 residências, sendo que dessas, 40 (dez em cada um dos quatro bairros escolhidos) aceitaram participar da pesquisa.

\section{Coleta e análise de dados}

A coleta de dados foi realizada por meio de entrevistas individuais, com a utilização de um roteiro semiestruturado. As entrevistas aconteceram no interior das residências, foram gravadas e transcritas integralmente para posterior análise. A coleta de dados aconteceu em duas etapas: as dez primeiras entrevistas (MSe) foram realizadas entre outubro e novembro de 2004 e as outras 30, em agosto e setembro de 2005 (ICa, ST e JC). O tempo médio de gravação de cada entrevista foi de 30 minutos. Cada visita domiciliar teve a duração média de 60 minutos.

A análise dos dados foi feita concomitantemente à sua coleta, quando foram realizados: tabulação, tratamento e elaboração dos resultados a partir dos depoimentos gravados e transcritos. Para a tabulação dos dados, foram utilizados os Instrumentos de Análise de Discurso (IAD1 e IAD2), etapa da técnica do Discurso do Sujeito Coletivo. A seguir, procedeu-se à análise, com o desenvolvimento de discussões com a aproximação à fundamentação teórica, tomandose como referência as elaborações conscientes dos diferentes sujeitos acerca dos cuidados domiciliares com a água de consumo humano e suas implicações na saúde. Os trechos dos discursos apresentados foram transcritos dos depoimentos, sem correção gramatical ou ortográfica.

\section{Resultados e discussão}

\section{Características dos entrevistados}

As características dos entrevistados dos quatro grupos estudados são apresentadas na Tabela 1 .

Todos os domicílios são atendidos pelo sistema público de abastecimento de água gerenciado pela Cesan. Em ICa, dois domicílios utilizam a água proveniente da casa do vizinho (ligações clandestinas por eles denominadas de "gato" e que não pagam por esse consumo) e, em ST, seis dos domicílios dividem a mesma ligação de água, assim como o valor da conta mensal, com um parente ou vizinho.

Observa-se que a relação entre o valor da conta mensal de água e renda mensal familiar é mais expressiva em ICa $(2,7 \%)$ e em ST $(2,3 \%)$ do que em JC (1,4\%), onde o nível socioeconômico é mais alto. Os grupos de pessoas mais carentes, além de possuírem renda familiar mais baixa, pagam mais para ter o acesso à água, ou seja, quanto mais pobre, mais se paga pela água. De acordo com o Relatório de Desenvolvimento Humano de 2006 (RDH) do Programa das Nações Unidas para o Desenvolvimento (PNUD), o princípio perverso que 
Tabela 1 - Características dos entrevistados por área de estudo: MSe, ICa, ST e JC

\begin{tabular}{|c|c|c|c|c|c|}
\hline \multirow{2}{*}{ Características dos entrevistados } & & \multicolumn{4}{|c|}{ Área de estudo/ Número de entrevistados } \\
\hline & & $\begin{array}{c}\text { MSe } \\
(\text { Total }=10)\end{array}$ & $\begin{array}{c}\text { ICa } \\
(\text { Total }=10)\end{array}$ & $\begin{array}{c}\text { ST } \\
(\text { Total }=10)\end{array}$ & \multirow{2}{*}{$\begin{array}{c}\text { JC } \\
(\text { Total }=10)\end{array}$} \\
\hline \multirow{3}{*}{ Sexo } & & & & & \\
\hline & Masculino & 0 & 1 & 0 & 1 \\
\hline & Feminino & 10 & 9 & 10 & 9 \\
\hline \multirow[t]{3}{*}{ Idade (anos) } & Mínima & 25 & 32 & 24 & 27 \\
\hline & Máxima & 63 & 74 & 69 & 80 \\
\hline & Média & 39 & 46 & 38 & 56 \\
\hline Tempo de residência no bairro (anos) & Média & * & 40 & 21 & 33 \\
\hline \multirow[t]{3}{*}{ Renda mensal familiar $(\mathrm{R} \$) * *$} & Mínima & & 250 & 300 & $3.000,009.000,00$ \\
\hline & Máxima & * & $3.000,00$ & 900 & $4.900,00$ \\
\hline & Média & & 815 & 575 & \\
\hline \multirow[t]{3}{*}{ Custo mensal da conta de água $(\mathrm{R} \$)^{* *}$} & Mínima & 7 & 8 & 3 & 25 \\
\hline & Máxima & 55 & 40 & 34 & 178 \\
\hline & Média & 27,07 & 21,69 & 13,4 & 69,57 \\
\hline \multirow[t]{6}{*}{ Nível de escolaridade } & Analfabeto & 0 & 1 & 1 & 0 \\
\hline & 1ㅇ grau incompleto & 5 & 9 & 4 & 3 \\
\hline & 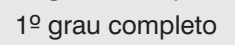 & 2 & 0 & 1 & 1 \\
\hline & $2^{\circ}$ grau incompleto & 2 & 0 & 1 & 0 \\
\hline & $2^{\mathrm{o}}$ grau completo & 1 & 0 & 3 & 1 \\
\hline & Superior & 0 & 0 & 0 & 5 \\
\hline Pessoas residentes no domicílio & Média & 4 & 6 & 4 & 4 \\
\hline Televisão ou rádio ligado & & 8 & 6 & 7 & 3 \\
\hline \multirow[t]{2}{*}{ Existência de hidrômetro } & Sim & 9 & 10 & 9 & 10 \\
\hline & Não & 1 & 0 & 1 & 0 \\
\hline \multirow[t]{2}{*}{ Existência de reservatório domiciliar } & Sim & 5 & 6 & 6 & 10 \\
\hline & Não & 5 & 4 & 4 & 0 \\
\hline \multirow[t]{2}{*}{ Uso de filtro domiciliar } & Sim & 4 & 5 & 7 & 10 \\
\hline & Não & 6 & 5 & 3 & 0 \\
\hline
\end{tabular}

*Dado não levantado; ** câmbio médio na época da entrevista: (09/2005): $1 €=R \$ 2,70$.

se aplica a grande parte do mundo em desenvolvimento é que as pessoas mais pobres não só têm acesso a menos água e a menos água potável, como também pagam algumas das tarifas mais elevadas do mundo. É interessante destacar o que concluiu esse Relatório: "O que acontece em muitos países é que as pessoas carentes recebem menos, pagam mais e suportam o fardo dos custos de desenvolvimento humano associados à escassez" (PROGRAMA DAS NAÇÕES UNIDAS PARA O DESENVOLVIMENTO, 2006, p. 3). Esse Relatório propõe a introdução de tarifas subsidiadas, subsídios cruzados e investimentos em fontes públicas para garantir que ninguém seja impedido de ter acesso à água devido à pobreza, com uma despesa máxima em água de $3 \%$ do rendimento familiar.

\section{Percepções dos entrevistados}

\section{Sobre a água de consumo humano}

As percepções dos entrevistados sobre a água de consumo humano por ideia central e ancoragem estão presentes na Tabela 2.

\section{Sobre a qualidade da água da Cesan}

Os depoimentos mostram as percepções sobre a qualidade da água sob dois principais ângulos. O primeiro é de que normalmente a água se apresenta em boa qualidade, e o outro é que, após a ocorrência de interrupção no sistema de abastecimento público, a água se apresenta com alguma alteração nas características consideradas 'normais'.

A maioria dos entrevistados (30/40) acha que a água da Cesan é boa, e associa essa qualidade ao tratamento que recebe antes de chegar às suas casas:

Olha, eu acho muito boa, porque é uma água tratada... Você nem paga o valor que tem ser pago por ela! (MSe); A água da Cesan, eu acho ótima, não é?... Aquele aspecto assim, muito bonito! Maravilhosa! (ICa); Eu não tenho o que reclamar, não! (ST).

Entretanto, existem aqueles que percebem a água como limpa, mas podendo apresentar alguma alteração (19/40). A percepção da falta da qualidade da água que chega à torneira e suas implicações estão presentes nos depoimentos, associadas ao sabor, cor, material em suspensão, contaminação bacteriológica ou problemas anteriores de saúde. Rocha et al. (2006) também identificaram, em depoimentos de moradores, as características físicas (cor, odor, sabor e material em suspensão) como importantes para avaliar a qualidade da água. Observa-se a desconfiança quanto à qualidade da água sob 
Tabela 2 - A qualidade da água de consumo humano: síntese das ideias centrais e ancoragens por área de estudo

\begin{tabular}{|c|c|c|c|c|c|c|}
\hline \multirow{2}{*}{ Ideia central } & & \multirow{2}{*}{ Ancoragem } & \multicolumn{4}{|c|}{ Número de entrevistados/área } \\
\hline & & & MSe & $\mathrm{ICa}$ & ST & $\mathrm{JC}$ \\
\hline \multirow[t]{3}{*}{ A qualidade da água da Cesan } & É boa & & 7 & 7 & 8 & 8 \\
\hline & $\begin{array}{l}\text { É limpa, mas pode apresentar } \\
\text { alguma alteração }\end{array}$ & & 3 & 5 & 6 & 5 \\
\hline & Não é boa & & - & 1 & - & 2 \\
\hline \multirow{2}{*}{$\begin{array}{l}\text { Diferença entre a água de beber e } \\
\text { a água para outros usos }\end{array}$} & Existe & & 6 & 4 & 9 & 9 \\
\hline & Não existe & & 3 & 6 & 1 & - \\
\hline \multirow[t]{5}{*}{ A água que se bebe } & Filtro domiciliar & & 4 & 5 & 6 & 6 \\
\hline & Água da torneira & & - & 1 & 1 & - \\
\hline & Água envasada & Mídia & 2 & 2 & 3 & 4 \\
\hline & Água fervida & & - & 1 & - & - \\
\hline & Água de torneira coada com um pano & & 1 & 1 & - & - \\
\hline \multirow{9}{*}{$\begin{array}{l}\text { A água que é considerada boa } \\
\text { para o consumo humano }\end{array}$} & Tem que ser limpa & & 2 & 1 & - & - \\
\hline & Tem que ser limpa e filtrada & & 4 & 3 & 2 & 2 \\
\hline & Tem que ser tratada & & 1 & 2 & 3 & 4 \\
\hline & Teria que ter um tratamento específico & & 1 & - & - & - \\
\hline & É a que consome & & 2 & 1 & - & -- \\
\hline & Tem que ser potável & & - & 1 & - & - \\
\hline & É a água de mina & Experiência de vida & - & - & 1 & 2 \\
\hline & É a envasada & Mídia & - & 1 & 4 & 1 \\
\hline & Não sabe dizer & & - & 1 & 1 & 1 \\
\hline
\end{tabular}

o aspecto bacteriológico, mesmo apresentando aspecto considerado por eles 'normal':

Ah, na maioria das vezes normal, assim, não é? Ah, sem aparência de nada, visivelmente, nada, não é?... Mas às vezes ela vem barrenta, mas não sei ali, não é? Se for pesquisar mesmo, fazer, assim, um teste, se... Mas, provavelmente encontrará assim, algo assim, alguma bactéria, não é? ... Bom, às vezes assim, com algum gosto forte, não é? ... Mas o que eu penso disso aí, é para matar à vezes algum micróbio... Que eles põem lá na caixa d'água, não é? (MSe); Oh, tem época que ela... Ela é uma água que ela vem meia suja, não é? (ICa); Olha, às vezes cai limpinha, às vezes ela cai um pouco barrenta, quando ela falta, que começa a vir de novo, ela cai um pouco, com bastante sujeira... (ST); Quando chove, sim, aí fica aquela água suja porque choveu, não é?... Tem hora que ela está mais amarelinha, tem hora que ela está mais branquinha, com um cheiro muito forte de cloro... Acho que tem que ser um pouquinho mais tratada... Porque tem falhas... E ela é tratada e nós pagamos isso aí, não é?... (JC).

Percebe-se que os entrevistados sabem da existência de organismos que podem ser prejudiciais à saúde, mesmo que não possam ser vistos a olho nu. Há também a preocupação em relação à possibilidade do risco de transmissão de doenças pela água. Os entrevistados atentam para momentos em que percebem gosto na água, fazendo associação com a presença de cloro. Os depoimentos apontam para os transtornos que ocorrem na intermitência da água, na influência das chuvas e na utilização do cloro como elemento eliminador de micro-organismos prejudiciais à saúde. Registram a falta de confiança na água recebida, até mesmo depois de filtrada, como também o risco a que está exposta a população quando há interrupção do serviço de abastecimento público de água. Mas, apesar de terem consciência disso, os entrevistados não tomam outra providência além de esperarem a água escoar e voltar ao aspecto de limpeza ao qual estão acostumados. Somente no discurso de JC aparece a ideia de água como serviço, pois foi ressaltado que os moradores pagam pelo direito de recebê-la sempre com qualidade.

Entretanto, existem aqueles que dizem que a água da Cesan não é boa (3/40) e sempre associam a falta de qualidade às suas características organolépticas.

Ah, eu acho que não está sendo boa não, está vindo com muito cloro, entendeu? Não tem como beber não, muito cloro. Acho que faz até mal, não é? (ICa); Ah, tem dia que está barrenta... Agora o barro eu acho que é por causa da chuva, eu não sei se eles mexem lá também... (JC).

Johnson (2003), em New Jersey (EUA), concluiu que as informações sobre a qualidade da água preocupam os consumidores e podem mudar atitudes e comportamentos. McGuire (1995), também nos EUA, alerta para o fato de que, se os consumidores detectam a presença de sabor na água, eles podem acreditar que a água não é segura. Melaku e Ismail (2002), na Etiópia, mostram que as consequências do consumo de água provinda de fontes não-seguras são claramente entendidas pelos entrevistados. Discutem, por outro lado, sobre a existência de uma lacuna entre o conhecimento e a preocupação 
(baseada em uma percepção errada) com o sabor do cloro na água de consumo, daí a necessidade de programas educacionais que possam dar ênfase a essa questão. Strang (2004) afirma que o gosto das águas naturais é mais comumente aceito e, quanto à água de torneira, acredita-se que, pelo fato de a água ter sido captada, tratada e distribuída, ela possa ter sofrido adulteração e ter tido a sua "naturalidade" comprometida. Piriou et al. (2004), na França e nos EUA, afirmam que o sabor de cloro na água de torneira é causa de reclamação e insatisfação. Levallois, Grondin e Gingras (1999), no Quebec, Canadá, obtiveram resultados de insatisfação com a água de torneira em 50\% dos consumidores entrevistados, enquanto estudo realizado por Jones et al. (2005) mostra que a preocupação mais forte dos participantes da pesquisa realizada no Canadá, com relação à qualidade da água, foi a contaminação bacteriana e química e seus efeitos negativos à saúde. Também a pesquisa da Gallup Organization's (2003) mostra que os estadunidenses se preocupam mais com a qualidade da água em relação às questões referentes à saúde seguida pelo sabor e pelo conforto.

\section{Sobre a água que se bebe}

Quanto à água utilizada para beber, surgem diferentes percepções. A água precisa ser filtrada para o consumo (21/40), pois os entrevistados afirmam que ela vem limpa para todos os usos, exceto para beber. Para este fim, seria necessário que a água fosse um pouco mais limpa. Acham que a água muda de aspecto ao passar pelo filtro domiciliar. Segundo eles, é necessário filtrá-la, pois é possível que a água da Cesan venha com micro-organismos e possa trazer algum prejuízo à saúde.

Ela vem limpa assim, para lavar, não é? Para cozinhar, agora para gente consumir ela, não vem totalmente para gente consumir ela, não é?... Tem que limpar mais um pouquinho, não é? Quando a água da rua, ela vem às vezes um pouco amarelinha, e tal, e a água já filtrada que a gente bota assim no filtro, aquela água branquinha, não é? Mesmo ela passando pelo aquele processo da Cesan, a gente tem que filtrar, não é? Por causa da saúde da gente. Eu acho que para gente tomar tem que ser filtrada. Porque você vai tomar água direta da torneira? E as bactérias?... É porque não dá para ver, não é? A gente vê que é limpa, mas só através de microscópio para ver se tem alguma coisa ali! (MSe).

Há quem declare que bebe a água diretamente da torneira (2/40): Para mim não existe não, porque eu bebo da torneira (risos) (ICa).

Mas há aqueles que compram água envasada (11/40). Interessante constatar que isso é feito mesmo com dificuldades financeiras que enfrentam para adquirir elementos mínimos à sobrevivência. Os entrevistados justificam isso dizendo que a água envasada tem gosto diferente, e até atribuem a isso uma eventual falsa impressão. Na opinião deles, o correto seria utilizar a água envasada para uso também no preparo de alimentos, mas dizem que isso seria muito caro.

Eu prefiro comprar água mineral para tomar. Ué, porque você já não pode comprar água mineral para fazer outras coisas, fazer comida, que seria o correto, não é? Aí, se você compra pelo menos para você tomar, já ajuda, não é? Porque se você for comparar uma água mineral, ela é diferente da água da Cesan, que vem da rua. Ah, sei lá! Parece que ela é mais... Gostosa, a água mineral. Deve ser sim, às vezes, quisicológico, não é? (MSe); A água que a gente compra é bem melhor! Especial, eles falam, não é? Eu não sei! Ela tem um gosto diferente (ICa); Eu uso a água encanada só para uso doméstico mesmo, entendeu?(ST); Se a da Cesan fosse mais limpa, não é? Uma água menos poluída, a gente poderia estar usando a da Cesan, também! (JC).

Interessante observar a crença das pessoas na qualidade da água envasada, que criam fantasias sobre seu gosto ou mesmo sonham possuir um nível socioeconômico mais elevado para consumir apenas esse tipo. Nos períodos em que foram realizadas as entrevistas, era comum observar, transitando nas ruas, os caminhões de revenda de água envasada. Na área de ST, que é uma região de característica topográfica acidentada, observavam-se caminhões de menor porte, dada a dificuldade de circulação pelas ruas estreitas e íngremes, sempre com música anunciando a sua passagem. É interessante destacar que o custo de $1 \mathrm{~L}$ de água envasada oscila em torno de R\$ 1,20, enquanto, a título de exemplo, um sujeito de ST, usuário de água envasada, paga ao serviço público de água o valor de R \$ 5,69 por $12 \mathrm{~m}$ 3/mês. Ou seja, consome $12.000 \mathrm{~L}$ de água pelo custo da aquisição de cerca de $5 \mathrm{~L}$ de água envasada. Considerando essa residência, onde moram duas pessoas, e que cada uma bebe de 1 a 2 L de água por dia, chega-se ao consumo mensal aproximado de 90 L. Isso representa, no caso da água envasada, um custo mensal de cerca de $\mathrm{R} \$ 100,00$, quase 20 vezes o valor da conta mensal paga ao serviço de água. Além disso, é necessário considerar o risco a que essas pessoas podem estar sujeitas com relação à inadequada qualidade da água envasada escolhida para o seu consumo, ou mesmo as formas de manuseio no domicílio. Nas áreas de MSe, ICa e ST, onde a renda mensal é bem inferior à de JC, esse custo é significativo no orçamento familiar.

O hábito do uso da água envasada é considerado, na modernidade, um fenômeno social, dado o crescimento exorbitante de seu consumo em várias partes do mundo. $\mathrm{O}$ consumo de água envasada reflete um tipo de modo de vida. A Europa tem uma longa tradição em seu uso, mas, atualmente, esse hábito vem se estendendo ao redor do mundo. Em geral, os consumidores pensam que o sabor é melhor, principalmente pela não-presença do cloro e, às vezes, acreditam que seja mais segura do que a água de torneira (FERRIER, 2001). A literatura registra estudos que apontam a preferência do consumidor pelas 
águas envasadas e apresentam resultados de presença de contaminação em algumas delas, como mostra Raj (2005) sobre contaminação bacteriológica, Shotyk, Krachler e Chen (2006) sobre componentes químicos orgânicos e inorgânicos, e Sanchez et al. (1999) sobre a detecção de radioatividade.

Há um depoimento em que aparece a prioridade do uso da água envasada para as crianças. Caso não se tenha dinheiro suficiente para comprá-la para todos os moradores do domicílio, os adultos consomem água do sistema: Para beber, a gente às vezes até bebe, a gente vai na torneira pega água e bebe às vezes, agora para ela e o menorzinho eu dou água mineral. Porque são pequeninho, não é? (ICa).

Foi registrado, também, um sujeito que declara que, para os visitantes, também é oferecida água do sistema público de abastecimento: Às vezes chega alguém, assim, eu tenho pouca água no galão, lá no bebedouro, ai eu dou da água gelada que tem na geladeira, que é do filtro, entendeu? (ST).

Há um depoimento que apresenta a alternativa de fervura da água para consumo: Mas, geralmente, eu fervo a água e boto na geladeira (ICa). Nichter (1985) discute a prática de fervura da água e como as mensagens de saúde pública são assimiladas pela população de países em desenvolvimento. O autor alerta para os prejuízos que podem ser trazidos à população quando essas informações são mal interpretadas. Há também dois outros entrevistados cuja alternativa é coar a água.

\footnotetext{
Até botei um paninho ali na pia, eu estou com medo, eu tenho que comprar um filtro urgente, mas eu estou usando ela assim (MSe); Bom, por enquanto eu estou sem o filtro. Eu estou pegando água da torneira mesmo, da Cesan, não é?... Mesmo assim, eu boto um paninho assim, na boca da torneira, para coar mais ainda, não é? (ICa).
}

É interessante atentar para esses depoimentos, pois mostram como a falta de informação pode contribuir para a exposição das pessoas ao risco de adoecer. Os sujeitos têm consciência do risco, mas tomam providências muitas vezes não-recomendadas pelos procedimentos técnicos ou orientações oficiais: foi observado um tecido amarrado na torneira da pia da cozinha. O hábito de coar a água, prática adotada com o uso de tecido na torneira, é passível de contaminação por bactérias patogênicas, como mostram Islam et al. (2001) apud Trevett, Carter e Tyrrel (2005).

\section{Sobre a água que é considerada boa para o consumo humano}

Há quem diga que a água boa para o consumo humano tem que ser limpa (3/40): Ah, deve ser limpa, não é? Aquela água clarinha, sem o gosto, não é?... Sem bactéria, ai é boa, não é? Porque sempre tem bactéria (MSe); Clara, de bom aspecto, não é? (ICa). Há outros que acreditam que, além de limpa, a água deva ser filtrada (11/40).
Ah, eu acho que tem que ser bem filtrada, quando vem para mim, não é? Já da estação. Ah, por causa das bactérias... (risos) (MSe); Eu acho que tem que fazer a limpeza, filtrar, que seja bem feita, nãoé? (JC).

Uma água boa para o consumo humano tem que ser tratada. É o que também alguns dos entrevistados pensam (11/40).

Que eu considero assim, uma água bem tratada, não é? Livre de contaminação, sem risco de pegar uma hepatite, uma verme, não é?... Sem gosto, sem cor e tratada. Uma água bem tratada, não é? (JC).

Há, ainda, quem opine que a água teria que ter um tratamento específico (1/40).

Uma água boa? Ela tinha que vir já feito um tratamento específico desde lá da Cesan, para jogar para gente. A minha água eu considero boa, só... Igual eu estou te falando, eu só não considero ela boa para gente tomar, para gente beber... Você pegar direto... (MSe).

E somente um sujeito em ICa declara que uma água boa para o consumo humano tem que ser potável. Entretanto, alguns consideram boa para o consumo humano a água de que utiliza no momento: Uma água limpa, água assim, igual a da gente, água da Cesan mesmo (ICa).

Há quem declare que uma água boa para o consumo humano é a água proveniente de mina (3/40).

A água boa mesmo de qualidade da gente consumir é aquela lá da roça, que a gente bebia lá nas fontes de inhame, aquilo que era água, não é? (ST); Para se beber uma água como antigamente, a gente acredita que existe assim, não é? Tirar da fonte e beber, não é? (JC).

Há os que acreditam que uma água boa para o consumo humano é a água envasada (6/40): Olha, se eu tivesse condição, hoje, de ter na minha casa só água mineral... Só usaria água mineral, entendeu? (MSe). Entretanto, há aqueles que não sabem dizer qual água é a boa para o consumo humano (3/40): Ih, aí eu não sei te explicar, não sei mesmo, vou ser sincera (ST).

\section{Sobre o uso do reservatório de água domiciliar}

As percepções dos entrevistados sobre o uso do reservatório de água domiciliar por ideia central e ancoragem apresentam-se na Tabela 3.

A limpeza do reservatório de água domiciliar é uma questão importante para os entrevistados, pois a maioria (32/40) mostra ter 
Tabela 3 - 0 uso do reservatório de água domiciliar: síntese das ideias centrais e ancoragens por área de estudo

\begin{tabular}{|c|c|c|c|c|c|c|}
\hline \multirow{2}{*}{ Ideia central } & & \multirow{2}{*}{ Ancoragem } & \multicolumn{4}{|c|}{ Número de entrevistados/área } \\
\hline & & & MSe & $\mathrm{ICa}$ & ST & JC \\
\hline \multirow{6}{*}{$\begin{array}{l}\text { O uso do } \\
\text { reservatório de } \\
\text { água domiciliar }\end{array}$} & É importante no caso de falta de água & \multirow[t]{6}{*}{ PSF } & 5 & 9 & 8 & 4 \\
\hline & Possibilita economizar água & & 1 & - & 1 & - \\
\hline & Se coberto contribui no controle da dengue & & 3 & 5 & 2 & 3 \\
\hline & Faz limpeza & & 6 & 10 & 8 & 8 \\
\hline & Não faz limpeza & & 1 & - & - & 1 \\
\hline & Tem por hábito & & - & - & - & 5 \\
\hline
\end{tabular}

consciência da importância desse procedimento para a garantia da qualidade da água recebida do sistema. Mas, infelizmente, ninguém a faz em conformidade com as recomendações, podendo eventualmente colocar em risco a saúde da família:

Todos de 3 em e 3 meses ou de 6 em 6 meses, a gente tira aquela tampa, eu lavo, seco ela bem secadinha, tiro tudo, o resíduo que tem, depois eu ligo de novo... Porque vem muita sujeira da rua... (MSe);

De vez em quando faço... Bom, a gente esvazeia a caixa, limpa ela todinha, e lava direitinho, com uma bucha por dentro, esfrega e tudo, ao redor dela todinha, aí, vou, enxugo ela direitinho com um pano bem limpinho, ou a gente joga uma pitadinha, um pouquinho de cloro dentro da água, para poder ajudar a matar os micóbios, aí tapo ela e depois bota para encher outra vez.... (ICa);

Retira a água todinha, aí se ficar uma sujeirinha no fundo, a gente passa um paninho e joga mais um pouquinho de água, até ela ficar limpinha e depois enche de novo... Eu costumo usar vinagre, depois que eu lavo ela todinha, eu enxáguo.... (ST);

Esvazia a caixa toda, bota a água toda para fora, entra dentro da caixa com a escova, escova toda ela, passa pano, limpa, joga água e enxágua ela, passa aquele cloro, deixa limpinha mesmo a caixa (JC).

Dois sujeitos declararam que não limpam o reservatório de água domiciliar.

Ah, eu fazia, ultimamente não estou fazendo não, já tem uns dois anos que eu vou te falar que eu não faço (MSe);

Olha, eu fazia até uns dois anos atrás, depois me disseram que não é muito bom fazer muita limpeza em caixa d'água... Já tem uns dois anos que eu não faço (JC).

Quanto à finalidade da existência do reservatório de água no domicílio, aparecem diferentes opiniões. A importância devido à falta de água é expressa por grande parte dos entrevistados (26/40).
Ah, porque a gente às vezes fica com medo de repente faltar água, e aí, como é que eu faço? Então, tendo a caixa, já dá para controlar melhor, em falta de água a gente tem que ter reserva ali, não é? (MSe); Que se houver um problema, quebrar um cano... A gente fica sem água, não é?... Porque acaba a água! (JC).

Entretanto, há quem declare em JC que tem o reservatório por hábito (5/40). A falta de conhecimento da real necessidade do uso de reservatório de água domiciliar pelos moradores de JC pode estar associada ao fato de que eles não enfrentam problemas com intermitência do serviço de abastecimento de água.

Ai, Meu Deus! Todo mundo precisa, (risos) não é?... Tem que ter caixa d'água, como que você vai ter uma água na casa se você não tem uma caixa d'água? Acho eu todo mundo tem, não é?... Ah, porque eu sempre desde que eu nasci, que eu moro em casa que tem caixa d'água, então, acostumei com caixa d'água, se eu não tivesse condição de ter caixa d'água, que que eu faria? (JC).

\section{Sobre 0 uso de 0 filtro domiciliar e a sua manutenção}

As percepções dos entrevistados sobre o uso do filtro de água domiciliar por ideia central e ancoragem estão na Tabela 4.

Quanto ao uso do filtro no domicílio, alguns entendem que o filtro retém "sujeiras" que vêm na água (18/40). Novamente, aparece nos depoimentos a preocupação com as crianças, mostrando o entendimento do sujeito acerca da sua vulnerabilidade ao contato com água sem qualidade:

Por causa das crianças. Porque elas não podem tomar água sem ser filtrada, não é? Porque talvez nessa água assim, sem ser filtrada, vem muito é... Alguma desidratação, não é? Se tiver o filtro, não vai eliminar, não é? A sujeira, qualquer tipo de micróbio, bactéria, que venha, não é? (MSe);

Ai, meu Deus, devido às impurezas dela, que ela vai chegar, não é? Ah, é porque a água fica muito tempo na caixa, junta aquele 
Tabela 4 - 0 uso do filtro de água domiciliar: síntese das ideias centrais e ancoragens por área de estudo

\begin{tabular}{|c|c|c|c|c|c|c|}
\hline \multirow{2}{*}{ Ideia central } & & \multirow{2}{*}{ Ancoragem } & \multicolumn{4}{|c|}{ Número de entrevistados/área } \\
\hline & & & MSe & $\mathrm{ICa}$ & ST & JC \\
\hline \multirow[t]{6}{*}{ O uso do filtro domiciliar } & Retém "sujeiras" que vêm na água & & 6 & 3 & 4 & 5 \\
\hline & Faz manutenção & & - & 4 & 6 & 10 \\
\hline & Não faz manutenção & & - & 1 & - & - \\
\hline & Usa por hábito & & - & 2 & 3 & 3 \\
\hline & Não usa & & - & 5 & 3 & - \\
\hline & A fervura elimina os micro-organismos da água & & - & 1 & - & - \\
\hline
\end{tabular}

limo grosso e mais a sujeira que tem, como é que a gente vai beber a água da caixa? (ICa);

É ... Porque a água não é totalmente limpa, nem servida para a gente beber diretamente, não é? Para evitar algum tipo de problema, não é? Verminose, alguma coisa, um bichozinho, porque a água bate na caixa da gente, mas de repente da caixa para cá costuma ter algum tipo de... Porque se eu beber ela com sujeira, me faz mal (ST);

É, porque essa água, eles falam que vem hidratada, mas a gente não tem tanta certeza. Porque por mais que diga que a água é boa, eu não confio na água não! (risos) Eu acho que filtrando a água é melhor, sai as impurezas, que tiver por acaso... Para água ficar mais... Mais própria para ser bebida, não é? (JC).

Cerca de metade dos entrevistados reconhecem a importância da manutenção do filtro domiciliar, mas nem todos detêm o conhecimento divulgado como correto para esse procedimento, cada um apresentando um modo diferente.

Faço. Eu lavo com bucha, sabão, e enxáguo ele, só! Ou eu lavo a vela com açúcar, assim, me ensinaram, não é?... Esfrego açúcar, tiro a sujeira todinha, enxáguo, passo água morna e boto no filtro de novo. Acho que de duas em duas semana, eu lavo ele, ou acho que é de 2 em 2 meses, ou toda semana (ICa); Porque ele fica tudo preto... Fica tudo cheio de lama. Eu lavo ele, às vezes com sabão em pó antes, e depois eu vou e lavo com açúcar também, eu passo açúcar com a buchinha, não é? (ST).

O uso de o filtro domiciliar por hábito também foi identificado nos depoimentos de oito entrevistados.

Porque eu gosto daquele gostinho que é diferente, sei lá, o sabor e também porque eu já me acostumei também a encher os canecos de água de lá... Ah, porque a minha avó me criou, com filtro de barro e eu quando casei, que tomei responsabilidade de mãe, eu comecei a comprar o filtro, quando ele está velho eu desfaço e compro outro (ICa).
Mas também há aqueles que não usam o filtro domiciliar (14/40): Infelizmente ainda não estou usando filtro não... Eu usava, mas agora uso mais não.... (ST).

O discurso sobre o uso do filtro mostra que as pessoas acham que ele retém as "sujeiras" que vêm na água do sistema de abastecimento (Se tiver o filtro, não vai eliminar, não é? A sujeira, qualquer tipo de micróbio, bactéria que venha, não é?), como também que a qualidade da água melhora após a sua passagem por ele (Aí, passaria para mim já limpinha...). Observa-se a preocupação com a limpeza do filtro (Eu troco a vela, porque tem o prazo para gente trocar ela, não pode usar a vela sempre, tem que trocar ela). Mas em nenhum depoimento transparece o conhecimento acerca da frequência de limpeza. É evidenciada, ainda, uma diversidade de maneiras de limpeza do filtro, assim como foi observado por Rocha et al. (2006).

$\mathrm{Na}$ maior parte dos depoimentos, o entendimento geral das pessoas sobre a importância do consumo de água com qualidade é claro, principalmente no que diz respeito ao risco à saúde. Mas observa-se, também, como a falta de conhecimento leva cada pessoa a procedimentos diversos na condução de suas formas de lidar com a água no domicílio. Mesmo recebendo-a com qualidade, isso pode levar o sujeito a um possível consumo de água sem qualidade, o que coloca em risco a sua saúde e a de sua família involuntariamente.

Há grande desconhecimento e despreparo dos entrevistados quanto aos cuidados domiciliares com a água de consumo humano. Este estudo mostrou que a educação sanitária dos entrevistados não está relacionada ao nível socioeconômico e à escolaridade. É necessário que a população tenha acesso às informações relativas aos seus direitos e deveres em sua relação com a água de consumo. Essa necessidade de conhecimento e busca de informações, pelo que dispõe a legislação sobre o direito do cidadão, é importante, como alerta Valadares (2000, p. 88) "para se sustentar, nem sempre o sujeito é um cidadão" e, ainda citando Soallheiros (1998), "há a lei e aquilo que não se consegue com a lei". Daí considerar a importância do exercício da cidadania pela população.

A busca de caminhos para que as pessoas venham a ter acesso a esses conhecimentos é necessária, lembrando da importância da contextualização discutida por Morin (1999). Nesse autor, é visto o caminho da reforma do pensamento pela reforma da educação. 
Faz-se necessário rever as formas hoje utilizadas para a informação da população, pois, como lembra Valadares (2000, p. 87), "sabemos que não bastam campanhas educativas para nos levar a uma retomada mais frutífera do sistema motor, conduzida por uma reflexão cada vez mais indispensável". Além do desenvolvimento de pesquisas que busquem melhorar a eficiência da qualidade da água de consumo, deve-se pensar como as pessoas podem alcançar conhecimentos que lhes possibilitem uma melhor qualidade de vida, pois, como salienta Valadares (2000, p. 95) "vivemos, entretanto, em um mundo onde as pessoas estão cada vez mais desapercebidas". Para o exercício de cidadania também se faz necessário o acesso à informação, pois o direito é legalmente garantido, porém não conhecido e exercido pela população.

Cabe ressaltar a influência da mídia nas declarações dos entrevistados. Apesar de alguns deles declararem ter informações pela televisão (Você ouviu? Saiu na televisão. Falou no rádio também! Não, do que? Vai faltar água! Economiza a água! Um sai avisando o outro. Graças a Deus aqui a comunicação é de todos), os depoimentos mostram que o fato de eles não terem conhecimento da legislação sobre a garantia da qualidade da água e dos seus deveres e direitos sobre o acesso à água de qualidade, as informações recebidas não permitem qualquer reflexão sobre essa questão, o que aponta uma falta de articulação entre as informações recebidas e os seus cotidianos. É importante informar que em 23 das 40 casas visitadas, a televisão estava ligada na hora da realização das entrevistas, lembrando que as entrevistas aconteceram todas no período da manhã, exceto na área de JC.

O desconhecimento da origem ou mesmo do processo ao qual a água é submetida antes de chegar ao domicílio é um fator importante a ser considerado pelos órgãos públicos de saúde e de saneamento para o investimento em atividades que possam promover a confiança do sujeito na qualidade da água que recebe, como também no entendimento da necessidade dos cuidados que ele precisa ter no domicílio para a garantia da continuidade da qualidade dessa água para o seu consumo. A falta de informação pode implicar em falta de confiança que muitos sujeitos mostram na qualidade da água que consomem. Assim, da mesma forma que é de grande importância o investimento realizado pelos serviços de saneamento para melhorar as tecnologias do sistema de abastecimento, é importante a preocupação em levar essas informações à população, promovendo a confiança do sujeito no uso da água do sistema público. Tal prática pode resultar em maior participação e apoio comunitário, bem como maior envolvimento do sujeito na gestão dos serviços de saneamento.

Além disso, a pessoa bem informada é capaz de fazer escolhas de maior custo-efetividade que lhe ofereçam melhor nível de proteção à saúde, o que pode evitar que muitos desses recorram a fontes inseguras de água para consumo. Isso, além de contribuir para a pessoa agir como cidadão, colabora para a reconstrução contínua do amor próprio e para a sua autonomia como sujeito participante e reivindicador de direitos, cumprindo deveres e, portanto, crescendo como pessoa humana. Para se aumentar a confiança e o envolvimento do cidadão na gestão pública, as entidades municipais, estaduais e federais devem utilizar mecanismos que promovam o diálogo, o aumento de consciência e a confiança na qualidade da água de consumo humano, também proporcionando ao sujeito a tomada de decisão com informação.

\section{Considerações finais}

As entrevistas e sua análise apontam a variedade de percepções e comportamentos dos entrevistados em relação à qualidade e origem da água que, em algumas situações, podem colocar a saúde em risco, além de acarretar gasto desnecessário com a aquisição de água envasada; falta de confiança na qualidade da água recebida, associada ao gosto e à presença de cor ou material sólido em suspensão, levando a pessoa a buscar diferentes formas de água para beber, seja direto da torneira, filtrada, fervida, envasada, ou até mesmo coada por um tecido amarrado na torneira. Isso aponta a necessidade de os órgãos públicos de saúde e os serviços de saneamento assegurarem a qualidade da água e investirem na divulgação de informações que garantam à população a confiança no consumo da água do sistema público, bem como o entendimento esclarecido das práticas de higiene no que diz respeito à limpeza do filtro e do reservatório de água domiciliar. Percebe-se claramente nos depoimentos a consciência da importância da limpeza desses equipamentos, porém os entrevistados não detêm o conhecimento dos procedimentos necessários a essas práticas, podendo até mesmo colocar em risco a saúde da família. Ressalta-se a necessidade de regulamentação por parte da saúde pública da fabricação e manutenção dos filtros domiciliares.

Os depoimentos apresentados evidenciam a falta de conhecimento da população acerca dos seus direitos e deveres em relação à água de consumo humano, como também a inefetividade dos meios de comunicação adotados pelo serviço de saneamento e pelas instituições de saúde locais. Ressalta-se a importância de se rever de que modo as informações devem ser veiculadas à população, já que a forma atual não vem facilitando o exercício da cidadania.

\section{Agradecimentos}

Os autores agradecem a participação dos moradores de Mangue Seco, Ilha das Caieiras, Santa Teresa e Jardim Camburi, ao apoio das agentes comunitárias de saúde e líderes comunitárias, à Secretaria de Estado da Saúde do Espírito Santo, à Secretaria Municipal de Saúde de Vitória, à Companhia Espírito Santense de Saneamento, à London School of Hygiene and Tropical Medicine of University of London, à Universidade Federal de Minas Gerais, ao Instituto Federal do Espírito Santo e ao apoio financeiro do Conselho Nacional de Desenvolvimento Científico e Tecnológico (CNPq) pela concessão de Bolsa para a primeira autora. 


\section{Referências}

AMARAL, L.A. et al. Água de consumo humano como fator de risco à saúde em propriedades rurais. Revista de Saúde Pública, São Paulo, v. 37, n. 4, p. 510-514, ago. 2003.

ASSOCIAÇÃO BRASILEIRA DE NORMAS TÉCNICAS (ABNT). NBR 5626, Instalação predial de água fria. Rio de Janeiro, 1998.

BRASIL. Ministério da Saúde. Decreto n. 5.440 de 4 de maio de 2005. Estabelece definições e procedimentos sobre o controle de qualidade da água de sistemas de abastecimento e institui mecanismos e instrumentos para divulgação de informação ao consumidor sobre a qualidade da água para consumo humano. Disponível em: < http:// www.funasa.gov.br/sitefunasa/legis/pdfs/ portarias_m/pm154402005. pdf $>$. Acesso em: 25 maio 2005.

Ministério da Saúde. Portaria n. 518 de 23 de março de 2004. Estabelece os procedimentos e responsabilidades relativas ao controle e vigilância da qualidade da água para consumo humano e seu padrão de potabilidade e dá outras providências. Disponível em: <http://www. funasa.gov.br/sitefunasa/legis/pdfs/portarias_m/ pm1518_2004.pdf > . Acesso em: 25 out. 2004.

CAMILOTTI, F.E.G.; GONÇALVES, M.L. A saúde pública e a qualidade da água em edificações na Cidade de Joinville. In: CONGRESSO DA ASSOCIAÇÃO BRASILEIRADEENGENHARIASANITÁRIAEAMBIENTAL, 22, 2003, Joinville. Anais... Rio de Janeiro: ABES, 2003. 1 CD-ROM.

FERRIER, C. Bottled water: understanding a social phenomenon. Discussion paper. WWF. 2001. Disponível em: <http://www.panda.org/ livingwaters/pubs/bottle_water.pdf > . Acesso em: 11 jun. 2005.

GALLUPORGANIZATION'S. Analysis and findings ofthe Gallup Organization's drinking water customer satisfaction survey. Pensilvânia, 2003. Disponível em: <www.epa.gov/safewater>. Acesso em: 4 nov. 2009.

GUSMÃO, P.T.R.; ARAGÃO, J.M.S.; MAGALHÃES, J.K.M. Filtro doméstico: Avaliação de sua eficácia e eficiência na remoção de agentes patogênicos. In: CONGRESSO DA ASSOCIAÇÃO BRASILEIRA DE ENGENHARIA SANITÁRIA E AMBIENTAL, 22, 2003, Joinville. Anais... Rio de Janeiro: ABES, 2003. 1 CD-ROM.

JOHNSON, B.B. Do reports on drinking water quality affect customers'concerns? Experiments in report content. Risk Analysis, [S. I.], v. 23, n. 5, p. 985-998, 2003

JONES, A.Q. et al. Public perception of drinking water from private water supplies: focus group analyses. BMC Public Health, London, v. 5, n. 129, 2005.

LEFÈVRE, F.; LEFÈVRE, A.M.C. O discurso do sujeito coletivo: um enfoque em pesquisa qualitativa (Desdobramentos). Caxias do Sul: ABDR, 2003.

LEVALLOIS, P.; GRONDIN, J.; GINGRAS, S. Evaluation of consumer attitudes on taste and at water alternatives in Québec. Water Science and Technology, London, v. 40, n. 6, p. 135-139, 1999.

MCGUIRE, M.J. Off-flavor as the consumer's measure of drinking water safety. Water Science and Technology, London, v. 31, n. 11, p. 1-8, 1995.
MELAKU, Z.; ISMAIL, S. Perception on fluoride related health problems in area of endemic fluorosis in Ethiopia: an exploratory qualitative study. Ethiopian Journal of Health Development, Addis Ababa, v. 16, n. 1, p 85-93, 2002

MORIN, E. Por uma reforma do pensamento. In: PENA-VEGA, A.; NASCIMENTO, E. P. (Org.) O pensar complexo: Edgard Morin e a crise da modernidade. 3. ed. Rio de Janeiro: Garamond, 1999, p. 21-34.

NICHTER, M. Drink boiled water: a cultural analysis of a health education message. Social Science and Medicine, [S. I.], v. 21, n. 6, p. 667-669, 1985

PIRIOU, P. et al. Chlorinous flavor perception in drinking water. Water Science and Technology, London, v. 49, n. 9, p. 321-328, 2004.

POSSEBOM, A. Poço no lugar de água encanada. A Gazeta, Vitória, 2 ago. 2004, Cidades, p. 4

PREFEITURA MUNICIPAL DE VITÓRIA. Município: Dados socioeconômicos e geográficos. Vitória, 2009. Disponível em: $<$ http://www.vitoria.es.gov.br/regionais/home.asp\#>. Acesso em: 4 nov. 2009

PROGRAMA DAS NAÇÕES UNIDAS PARA O DESENVOLVIMENTO (PNUD). Relatório do Desenvolvimento Humano 2006. Disponível em: <http://www.pnud.org.br/rdh/>. Acesso em: 4 nov. 2009.

QUEIROZ, J.T.M. Água de consumo humano distribuída à população e ocorrência de diarréia: Um estudo ecológico no município de Vitória/ ES. 2006. 131f. Dissertação (Mestrado em Saneamento) - Escola de Engenharia, Universidade Federal de Minas Gerais, Belo Horizonte, 2006.

RAJ. S.D. Bottled water: How safe is it? Water Environment Research, [S. I.], v. 77, n. 7, p. 3013-3018, 2005.

ROCHA, C.M.B.M. et al. Avaliação da qualidade da água e percepção higiênico-sanitária na área rural de Lavras/ MG, 1999-2000. Cadernos de Saúde Pública, Rio de Janeiro, v. 22, p. 1967-1978, set. 2006.

SA, L.L.C. et al. Qualidade microbiológica da água para consumo humano em duas áreas contempladas com intervenções de saneamento - Belém do Pará, Brasil. Epidemiologia e Serviços de Saúde, Brasília, v. 14, n. 3, p. 171-180, set. 2005

SANCHEZ, A.M. et al. Radioactivity in bottled mineral waters. Applied Radiation and Isotopes, [S. I.], v. 50, p. 1049-1055, 1999.

SANTOS, G.P.A.; COHEN, S.C.; CYNAMON, S.E. A qualidade da água na habitação como componente essencial para melhor qualidade de vida: Um estudo de gestão do sistema hídrico intra e peridomiciliar no loteamento de parque morada Anchieta. In: CONGRESSO DA ASSOCIAÇÃO BRASILEIRA DE ENGENHARIA SANITÁRIA E AMBIENTAL, 23, 2005 Campo Grande. Anais... Rio de Janeiro: ABES, 2005. 1 CD-ROM.

SHOTYK, W.; KRACHLER, M.; CHEN, B. Contamination of Canadian and European bottled waters with antimony from PET containers. Journal of Environmental Monitoring, London, v. 8, p. 288-292, 2006. 
SILVA, S.R. O papel do sujeito em relação à água de consumo humano: um estudo na cidade de Vitória-ES. 2007. 305f. Tese (Doutorado em Saneamento) - Escola de Engenharia, Universidade Federal de Minas Gerais, Belo Horizonte, 2007.

STRANG, V. The meaning of water. Oxford: Berg Publisher, 2004.

TESSAROLO, M. Água contaminada causa diarréia em crianças. A Gazeta, Vitória, 5 out. 1999, Grande Vitória, p. 6.
TREVETT, A.F.; CARTER, R.C.; TYRREL, S.F. The importance of domestic water quality management in the context of faecal-oral disease transmission. Journal of Water and Health, London, v. 3, n. 3, p. 259-270, 2005.

VALADARES, J.C. Qualidade do espaço e habitação humana. Ciência e Saúde Coletiva, Rio de Janeiro, v. 5, n. 1, p. 83-98, 2000.

VENTURIM, A. Água de nascente, um hábito que desafia o perigo. A Gazeta, Vitória, 28 jul. 2002, Estado, p. 10. 